\title{
Use of M-Health Technology for Preventive Medicine in Pakistan
}

\section{Mawani $\mathbf{M}^{*}$ and Masood Kadir $\mathbf{M}$}

Aga Khan University, Pakistan

\section{Dear Editor}

During last 10 years use of information and communication technologies have been on a rise not only worldwide but also in developing countries. Developing countries comprise of the largest proportion of world's mobile phone subscribers which is expected to increase further in the upcoming years [1]. The affordability and ease of maintainence have made cell phones quite popular in resource poor settings like Pakistan. According to Pakistan Telecommunication authority, as of august 2015 , about $62.5 \%$ of the population now owns a cellphone which has increased from $3.29 \%$ in 2004 [1]. Considering this, there is a great potential to utilize various attributes of mobile phone services such as; call, sms and data transfer capabilities, for health promotion and disease prevention. This will enable people to have more control over their health and thereby improve outcomes [2].

M-health(mobile health) has been defined by the Global Observatory for eHealth(GOe) as "medical and public health practice supported by mobile devices, such as mobile phones, patient monitoring devices, personal digital assistants (PDAs) and other wireless devices" [3]. In various developed countries, $m$-health has been found to be effective for targeting behavior change and improve compliance. For instance, it has been used in the management of diabetes, hypertension, asthma, eating disorders. Smoking cessation, weight loss, reduction of alcohol consumption and prevention of sexually transmitted diseases. There is an emerging evidence from a few developing countries as well [4].

While there is a promising evidence from developed and a few developing countries on the applicability of $\mathrm{m}$-health, there is a lack of published literature from Pakistan where it has a potential to bring improvement. First, it can provide acces to wider population at low cost which will be helpful in delivering health care interventions, specially in areas with lesser health resources, without requiring people to visit health services physically. While it is not always feasible for health care workers to physically visit some areas due to security reasons which is a public health challenge, a combination of physical visits as well as reaching out virtually through mobile technology can be quite beneficial [5]. It can be used for the capacity building of not just populations, but health systems as well in combination with other interventions such as awareness programs. For instance, it can be used for training LHWs to provide better care. There is a need however to compare effectiveness of $\mathrm{m}$-health with other interventions designed for behavior change for instance 'home visits by community workers'.

\section{References}

1. Deglise C, Suggs LS, Odermatt $P$ (2012) Short message service (SMS) applications for disease prevention in developing countries. J Med Internet Res 14: e3.

2. http://www.pta.gov.pk/index.php?ltemid=599

3. WHO (2011) mHealth: New horizons for health through mobile technologies. In Series WGOfe, ed. Geneva.

4. Free C, Phillips G, Felix L, Galli L, Patel V, et al. (2010) The effectiveness of M-health technologies for improving health and health services: A systematic review protocol. BMC Res Notes 3:250.

5. Mansoor H (2014) 28 city doctors killed in targeted attacks over four years. DAWN.
*Corresponding author: Minaz Mawani, Aga Khan University, Pakistan, Tel: +923450310193; E-mail: minaz.mawani@aku.edu

Received September 28, 2016; Accepted November 21, 2016; Published November 28, 2016

Citation: Mawani M, Masood Kadir M (2016) Use of M-Health Technology for Preventive Medicine in Pakistan. Health Care Current Reviews 4: 178. doi: 10.4172/2375-4273.1000178

Copyright: @ 2016 Mawani M, et al. This is an open-access article distributed under the terms of the Creative Commons Attribution License, which permits unrestricted use, distribution, and reproduction in any medium, provided the original author and source are credited. 